\title{
Hypoxia-induced miR-210 in epithelial ovarian cancer enhances cancer cell viability via promoting proliferation and inhibiting apoptosis
}

\author{
LI'AN LI, KE HUANG, YANQIN YOU, XIAOYU FU, LINGYUN HU, LEI SONG and YUANGUANG MENG \\ Department of Obstetrics and Gynecology, Chinese PLA General Hospital, Beijing 100853, P.R. China
}

Received January 13, 2014; Accepted March 11, 2014

DOI: $10.3892 /$ ijo.2014.2368

\begin{abstract}
R-210 is upregulated in a HIF-1 $\alpha$-dependent way in several types of cancers. In addition, upregulated miR-210 promotes cancer proliferation, via its anti-apoptotic effects. It is blind to the regulation of miR-210 under hypoxia conditions for ovarian cancer cells and to the effect of miR-210 on ovarian cancer growth. In the present study, we determined the expression of miR-210 in epithelial ovarian cancer specimens, and in ovarian cancer cell lines under hypoxia conditions, and determined in detail the effect of miR-210 overexpression on tumor cell proliferation, and the possible mechanisms of tumor growth by miR-210 regulation. It was shown that miR-210 expression is upregulated, in response to hypoxia conditions in epithelial ovarian cancer specimens as well as epithelial ovarian cancer cell lines, with an association to HIF-1 $\alpha$ overexpression. Furthermore, upregulated miR-210 promoted tumor growth in vitro via targeting PTPN1 and inhibiting apoptosis. Therefore, our findings shed light on the mechanism of ovarian cancer adaptation to hypoxia.
\end{abstract}

\section{Introduction}

Ovarian cancer (OC) is the most deadly gynecological malignancy, causing 140,200 estimated deaths worldwide every year (1). The non-specific symptoms of OCs, i.e., bloating and constipation, do not appear evident at the early stages of the disease, and early detection of the disease is also difficult, owing to the lack of specific and sensitive tests, and $75 \%$ of diagnosed cases are at late stages $(2,3)$. As current therapeutic approaches result in a median overall survival of only 2 to 4 years (3), and the search for novel diagnostic biomarkers is still on the way, it is of importance to deeply explore the pathogenesis and to screen novel therapeutic targets.

Correspondence to: Dr Yuanguang Meng, Department of Obstetrics and Gynecology, Chinese PLA General Hospital, 28 Fuxing Road, Beijing 100853, P.R. China

E-mail: yuangmeng2008@163.com

Key words: miR-210, hypoxia-inducible factor $1 \alpha$, epithelial ovarian cancer, apoptosis, tyrosine-protein phosphatase non-receptor type 1
The deregulated tumor growth brings tumor cells located away from vessels under hypoxic microenvironment, which drives cancer cells to undergo genetic and adaptive changes that allow them to survive and even proliferate in a hypoxic environment (4-6). Tumor hypoxia has become one of the key issues in the study of tumor physiology and cancer treatment. In recent years, a group of transcription factors has been reported to be implicated in regulating a wide array of genes responsible for the metabolic changes under hypoxia $(7,8)$. A pivotal component of these factors is hypoxia-inducible factor 1 (HIF-1), existing as a heterodimer composed of a constitutively expressed HIF-1 $\beta$ subunit and an oxygen sensitive HIF-1 $\alpha$ subunit. The HIF- $1 \alpha-\mathrm{HIF}-1 \beta$ dimer (9) binds to a conserved DNA consensus on the promoters of its target genes known as hypoxia-responsive element (10-12). HIF induces a vast array of gene products controlling essential cellular processes crucial for hypoxic adaptation (13). HIF-1 is a key regulator on the vascular endothelial growth factor (VEGF) and other angiogenic factors $(14,15)$ which play key roles in the growth and progression of solid tumors, including ovarian cancer (16-18). The HIF system has also been directly implicated in the responses of tumor cells to hypoxia $(6,19)$. Various cancers are characterized by enhanced HIF levels and increased expression of hypoxia-regulated genes which correlate both tumor aggression and patient outcome $(19,20)$. The role of HIF-1 has also been confirmed in upregulating ovarian cancer invasiveness (21-23), and the HIF-1 $\alpha$ overexpression is associated with a poor prognosis in patients with ovarian cancer (24). These reports suggest that HIF-1 is important for the acquisition of aggressive behavior in ovarian cancer cells. However, the mechanisms are not yet clear.

MicroRNAs (miRNAs) are about 22-nt endogenous non-coding RNAs that regulate gene expression (25) in a wide variety of organisms, including humans, and in a broad array of cell processes in mammals (26-28). miRNA expression signatures have been shown to be promising biomarkers for understanding the tumorgenesis of a wide array of human cancers $(29,30)$, including cervical cancer $(31,32)$. Recent years, numerous oncogenic microRNAs have been reported to be associated with cervical cancer tumorigenesis. miR-214 regulates ovarian cancer cell stemness by targeting p53/ Nanog (33); miR-376c enhances ovarian cancer cell survival by targeting activin receptor-like kinase 7 (34); and the 
downregulated miR-484 in ovarian cancer attenuates its knockdown in vascular endothelial growth factor $\beta$-subunit (VEGF $\beta$ ) and stimulates tumor endothelial cell growth and tumorigenesis (35). miR-210 is induced by hypoxia via HIF-1 $\alpha$ in normal cells, such as cardiomyocytes (36), keratinocyte (37) and other cells. It is significantly upregulated in pathophysiological situlations, especially in cancer cells, such as head and neck paragangliomas (38), lung cancer cells (39), and breast cancer cells (40). The upregulated miR-210 regulates cancer proliferation, via its anti-apoptotic effect (41), modulating angiogenesis (42), and is not affected by the regulation of miR-210 under hypoxia situation in ovarian cancer cells, or the miR-210 on ovarian cancer.

In the present study, we determined the miR-210 expression in epithelial ovarian cancer (EOC) specimens, and in ovarian cancer cell lines under hypoxia, and then determined in detail the influence of miR-210 overexpression on the tumor cell proliferation, and the possible mechanism of the miR-210 regulation on the tumor growth.

\section{Materials and methods}

Human tissue specimens. Utilization of all EOC and normal tissue specimens was approved by our hospital Internal Review Board (IRB) in Chinese PLA General Hospital. Before treatment by radiotherapy or chemotherapy, 48 human EOC tissue specimens were obtained by surgical resection. Twenty-two normal human ovarian tissue specimens were collected also by surgical resection. All tissue specimens were stored at $-70^{\circ} \mathrm{C}$.

Cell culture and treatment with reagents. The OVCAR-3 and SK-OV-3 EOC cell lines were provided by the cell resource center of Chinese Academy of Medical Sciences and were grown respectively in RPMI-1640 medium (Invitrogen, Carlsbad, CA, USA) and L-15 medium (Gibco, Grand Island, NY, USA) supplemented with $10 \%$ fetal bovine serum (FBS; Gibco, Rockville, MD, USA), $50 \mu \mathrm{g} / \mathrm{ml}$ penicillin and $50 \mu \mathrm{g} / \mathrm{ml}$ streptomycin. The cells were incubated at $37^{\circ} \mathrm{C}$, with $5 \% \mathrm{CO}_{2}$. For hypoxia treatment, cells were placed in a hypoxia incubator infused with a gas mixture of $5 \% \mathrm{CO}_{2}$ and nitrogen to obtain $3 \%$ oxygen concentration. Oxygen concentration was monitored continuously (Forma 3130; Thermo Scientific, Rockford, IL, USA). siHIF-1 $\alpha$, siHIF-2 $\alpha$ and siRNA control oligos were synthesized by GenePharma Technology (Shanghai, China) and were transfected into OVCAR-3 cells with at a concentraction of $40 \mathrm{nM}$ of lipofectamine 2000 to suppress the HIF-1 $\alpha$ or HIF-2 $\alpha$. miR-210 mimics (miR con as control) (Qiagen, Valencia, CA, USA) and miR-210 inhibitor (Sigma-Aldrich, St. Louis, MO, USA) were utilized to manipulate the miR-210 level. A total of 20 or $40 \mathrm{nM}$ miR-210 mimics/miR con, or $10 \mathrm{nM}$ miR-210 inhibitor was transfected into EOC cells with lipofectamine 2000. 5-FU (Sigma-Aldrich) was utilized to induce EOC apoptosis with a concentration of 5 or $40 \mu \mathrm{g} / \mathrm{ml}$.

RNA extraction and quantitative real-time polymerase chain reaction $(R T-q P C R)$. Total mRNA was extracted from tissue or cell samples by using the RNeasy mini kit (Qiagen). RT-qPCR analysis of the HIF- $1 \alpha$, HIF- $2 \alpha$, CASP3 or CASP9 expression in mRNA level was performed using SYBR-Green with the LightCycle 2.0 (Roche, Mannheim, Germany). All mRNA expression levels were normalized to GAPDH (glyceraldehyde-3-phosphate dehydrogenase). miRNA extraction was performed using the mirVana miRNA isolation kit (Ambion, Austin, TX, USA). Quantification of miR-210 expression was conducted using the mirVana qRT-PCR miRNA detection kit (Ambion), and the U6 small nuclear RNA was used as internal control. $\Delta \Delta \mathrm{Ct}$ method was used for relative quantification (43). A non-radioactive northern blot method, LED, for small RNA (about 15-40 bases) detection using digoxigenin (DIG)-labeled oligonucleotide probes containing locked nucleic acids (LNA) and 1-ethyl-3-(3-dimethylaminopropyl) carbodiimide was utilized to confirm the miR-210 and U6 expression, according to the protocol (44).

Protein isolation and western blot analysis. Whole cell extracts were prepared with a cell lysis reagent (Sigma-Aldrich) according to the manual; CASP3 or CASP9 were detected by western blot analysis using anti-CASP3, anti-CASP9 or anti-GAPDH rabbit polyclonal antibody (1:500; Sigma-Aldrich). Goat anti-rabbit IgG conjugated to horseradish peroxidase (Pierce, Rockford, IL, USA) and ECL detection systems (Super Signal West Femto; Pierce) were used for detection.

Cell colony formation, cell proliferation and cell apoptosis assay. For cell colony formation assay, $5 \times 10^{2}$ cells were incubated in 12 -well plates at $37^{\circ} \mathrm{C}$ containing $5 \% \mathrm{CO}_{2}$, and were transfected with 0 or $40 \mathrm{nM}$ miR-210 mimics or miR-210 control, 5-8 days post incubation; the cells were stained with crystal violet $(0.005 \%)$ for $20 \mathrm{~min}$ and recorded the colony numbers by imaging $\mathbf{J}$ software. For proliferation assay, post transfecting with miR-210 mimics or miR-210 control, cells were incubated in CCK-8 (Dojindo, Kumamoto, Japan). The $450 \mathrm{~nm}$ absorbance of each well was detected after visual color occurrence at 24,48 or 72 h. OVCAR-3 or SK-OV-3 cell apoptosis was examined with an Annexin V-FITC apoptosis detection kit (Sigma-Aldrich). Briefly, $1-5 \times 10^{5}$ cells were stained with Annexin V-FITC and propidium iodide and detected by a FACScan flow cytometer (BD Biosciences, Franklin Lakes, NJ, USA) to analyze cellular apoptosis. The results were calculated using CellQuest ${ }^{\mathrm{TM}}$ Pro software (BD Biosciences) and expressed as the percentage of apoptotic cells from the total cells.

Luciferase activity assay. For luciferase reporter experiments, according to the prediction to interact with miR-210, the 3 '-UTR or the mutated 3'-UTR of PTPN1 was amplified by PCR from human genomic DNA and inserted into the MluI and HindIII sites of pGL3 vector immediately downstream from the stop codon of luciferase. OVCAR-3 cells were cotransfected in 12 -well plates with $0.4 \mu \mathrm{g}$ of the firefly luciferase report vector and $0.1 \mu \mathrm{g}$ of the control vector containing Renilla luciferase, pRLTK (Promega, Madison, WI, USA) to eliminate differences in cell number and transfection efficiency, as well as with or without $40 \mathrm{nM}$ of miR-210 mimics or miR-con. At $24 \mathrm{~h}$ post-transfection, firefly and Renilla luciferase activities were measured consecutively using dualluciferase assays (Promega). Experiments were carried out in triplicate and means were determined. 
Table I. Correlation of miR-210 expression level in EOC patients with clinicopathologic parameters.

\begin{tabular}{|c|c|c|c|}
\hline Parameters & $\mathrm{n}$ or mean $\pm \mathrm{SD}$ & Relative miR-210 expression & p-value \\
\hline No. of patients & 48 & - & - \\
\hline Age at first diagnosis (years) & $57.2(7.1)$ & - & - \\
\hline \multicolumn{4}{|l|}{ Tumor stage } \\
\hline FIGO I & 5 & $1.64(0.52)$ & \multirow[t]{4}{*}{$0.01^{\mathrm{a}}$} \\
\hline FIGO II & 12 & $2.53(0.78)$ & \\
\hline FIGO III & 22 & $2.90(1.38)$ & \\
\hline FIGO IV & 7 & $3.85(1.66)$ & \\
\hline \multicolumn{4}{|l|}{$\begin{array}{l}\text { Post-operative residual } \\
\text { tumor size }(\mathrm{cm})^{\mathrm{b}}\end{array}$} \\
\hline$\leq 2$ & 25 & $2.12(0.98)$ & \multirow[t]{3}{*}{$0.05^{\mathrm{c}}$} \\
\hline$>2$ & 19 & $3.63(1.42)$ & \\
\hline Uncertain & 4 & & \\
\hline \multicolumn{4}{|l|}{ Histological grade } \\
\hline 1 & 6 & $2.43(0.93)$ & \multirow[t]{3}{*}{$0.3^{\mathrm{a}}$} \\
\hline 2 & 17 & $2.68(1.17)$ & \\
\hline 3 & 25 & $2.91(1.42)$ & \\
\hline \multicolumn{4}{|l|}{ Histological type } \\
\hline Serous & 22 & $2.92(1.24)$ & \multirow[t]{5}{*}{$0.2^{\mathrm{c}}$} \\
\hline Endometrioid & 5 & $2.98(1.53)$ & \\
\hline Mucinous & 8 & $2.25(0.94)$ & \\
\hline Clear cell & 4 & $1.9(0.88)$ & \\
\hline Other & 9 & $3.13(1.67)$ & \\
\hline
\end{tabular}

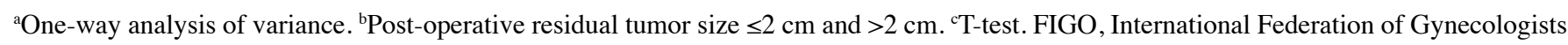
and Obstetricians; SD, standard deviation.

Statistical analysis. Statistical analyses were performed using SPSS16.0 software (IBM SPSS, Armonk, NY, USA). Correlations between miR-210 expression and the various clinical and laboratory data of patients with HIF-1 $\alpha$ were analyzed using the Spearman rank correlation. The HIF-1 $\alpha$, HIF-2 $\alpha$, CASP3 or CASP9 expression in mRNA level, the CASP3 or CASP9 expression in protein level, or miR-210 expression between two groups were analyzed by Student's t-test. A p-value $\leq 0.05$ was considered statistically significant.

\section{Results}

miR-210 is overexpressed in epithelial ovarian cancer specimens. We detected the expression of miR-210 in epithelial ovarian cancer tissues, compared to the normal ovarian tissues. Forty-eight primary EOC patients with a mean $( \pm$ SD) age of $57.2 \pm 7.1$ years at diagnosis were included in the study. Of these, five were FIGO stage I, 12 were stage II, 22 were stage III and seven were stage IV. Ovarian tissue samples from 22 healthy age-matched volunteers were used as controls. The mean $( \pm \mathrm{SD}) \Delta \Delta \mathrm{CT}$ value was $2.77 \pm 1.3$ in the 48 samples from patients with EOC and $1.00 \pm 0.42$ in healthy controls $(\mathrm{p}<0.01$; Fig. 1A). Thus, the miR-210 in ovarian tissue was significantly upregulated in patients with EOC. The miR-210 overexpression was correlated with the tumor stage or post-operative residual tumor size (Table I; $\mathrm{p}<0.01$ and $\mathrm{p}<0.05$, respectively).
To reconfirm the significant miR-210 upregulation in EOC, the miRNA samples were examined by northern blot analysis, and as shown in Fig. 1B the OC group was significantly higher than the normal group $(\mathrm{p}<0.05)$.

miR-210 expression correlates with a hypoxic signature in EOC and is upregulated by hypoxia in vitro. $\mathrm{miR}-210$ is induced by hypoxia via HIF-1 $\alpha(36,37)$. To assess the hypoxic regulation of hsa-miR-210 in EOC specimens, the HIF-1 $\alpha$ mRNA expression in the EOC and normal specimens was also determined by RT-qPCR. As shown in Fig. 1C, a significant high level of HIF- $1 \alpha$ mRNA was also confirmed ( $p<0.01)$. The correlation between miR-210 and of HIF-1 $\alpha$ mRNA expression was explored. In EOC patients, miR-210 expression showed a positive correlation with HIF- $1 \alpha$ mRNA $\left(\mathrm{R}^{2}=0.3054, \mathrm{p}<0.01\right)$ (Fig. 1D). To reconfirm the correlation of miR-210 expression with hypoxia in EOC, the miRNA samples from OVCAR-3 and SK-OV-3 under normoxia or hypoxia, were analyzed using quantitative-PCR (Q-PCR) too. In agreement with results of clinical specimens, we found a substantial and significant induction of miR-210 expression in two kinds of epithelial ovarian cancer cell lines under hypoxia (Fig. 2A and B). The in vitro results were also be reconfirmed by a HIF knockdown experiment. Effective siRNAs targeting HIF-1 $\alpha$ or HIF- $2 \alpha$ (Fig. 2C) abrogated the miR-210 induction by hypoxia $(\mathrm{p}<0.01$ and $\mathrm{p}<0.05$, respectively). 
A

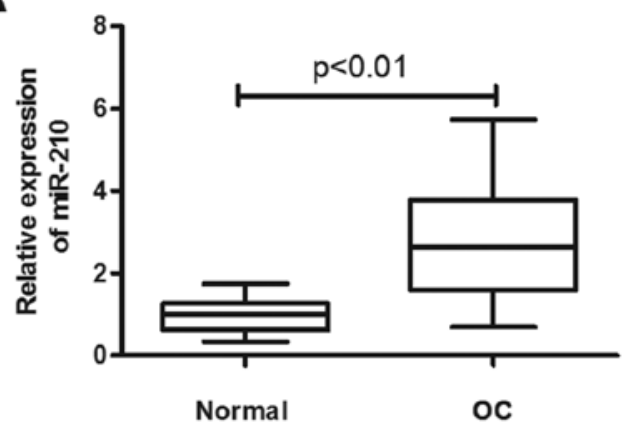

C

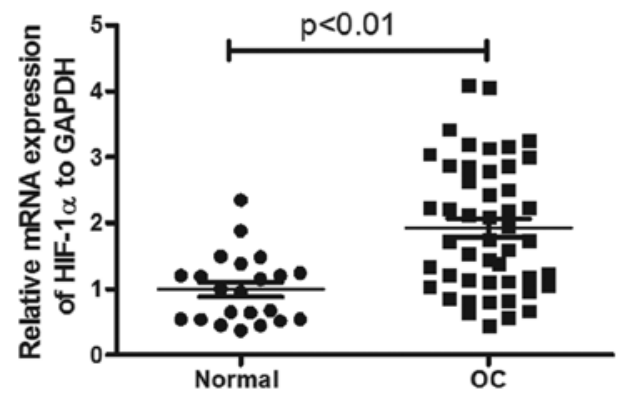

B
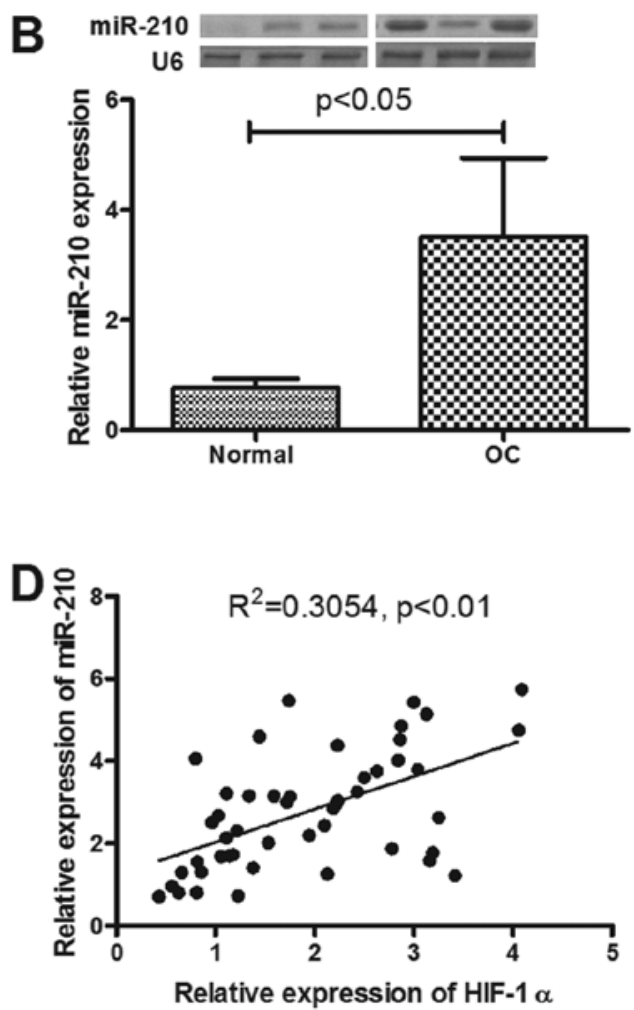

Figure 1. miR-210 is upregulated in ovarian cancer specimens and is positively correlated with HIF-1 $\alpha$ levels. (A) Relative miR-210 expression, examined by RT-qPCR, in normal ovarian tissue $(n=22)$ or ovarian cancer specimens $(n=48)$. (B) Increased miR-210 expression, revealed by northern blot analysis, in ovarian cancers. (C) HIF-1 $\alpha$ mRNA overexpression in ovarian cancer tissues (by RT-qPCR). (D) Correlation between the relative miR-210 expression with the HIF-1 $\alpha$ mRNA expression. All experiments were performed in triplicate and statistical significance was considered at $\mathrm{p}$-value $<0.05$.

A

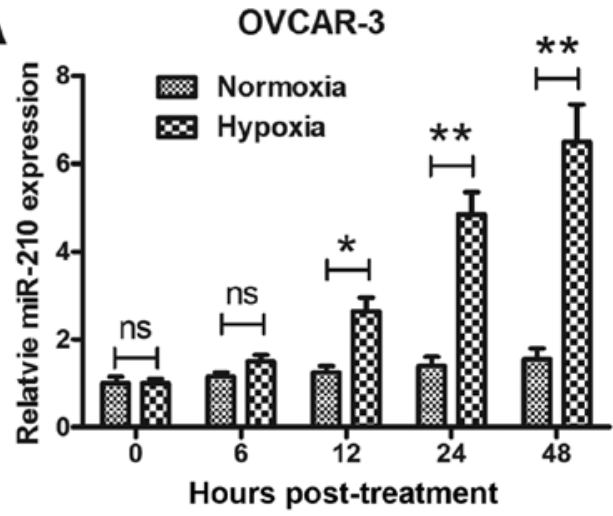

C



B

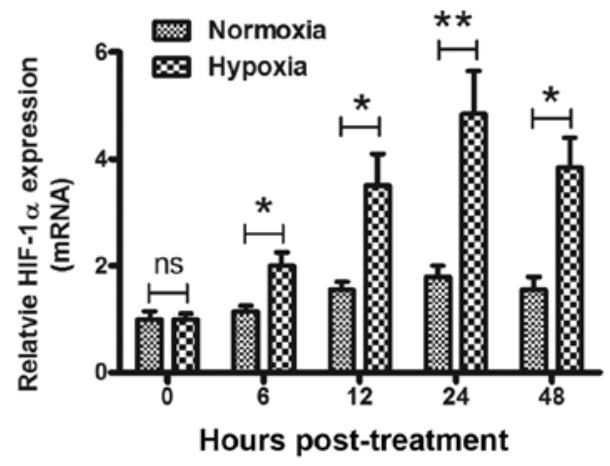

D

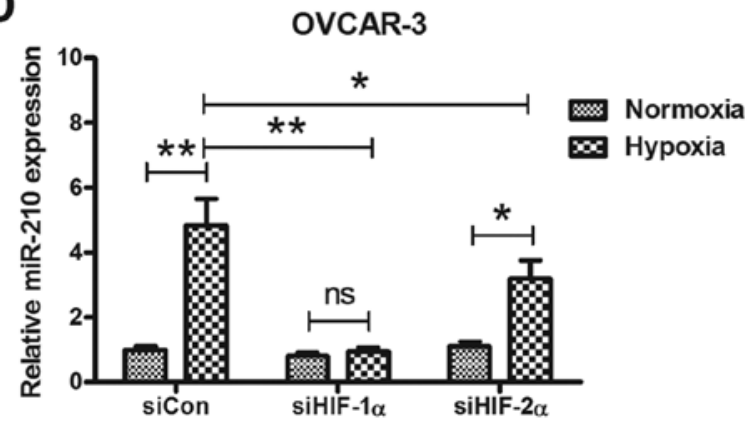

Figure 2. Hypoxia upregulates miR-210 expression in EOC cells HIF-dependently. (A) Hypoxia upregulates miR-210 expression (by RT-qPCR) in the EOC cell line OVCAR-3. (B) Hypoxia upregulates miR-210 expression (by RT-qPCR) in the EOC cell line SK-OV-3. (C) Knockdown of HIF-1 $\alpha$ or HIF-2 $\alpha$ (by RT-qPCR) by siRNA transfection for $24 \mathrm{~h}$ in OVCAR-3 cells. (D) Abrogation of miR-210 induction by hypoxia by the knockdown of HIF-1 $\alpha$ or HIF-2 $\alpha$ (transfection of siHIF1 $\alpha$, siHIF- $2 \alpha$ or siCon for $24 \mathrm{~h}$ ). The experiments were performed in triplicate. Statistical significance, ${ }^{*} \mathrm{p}<0.05$ and ${ }^{* *} \mathrm{p}<0.01$. 
A
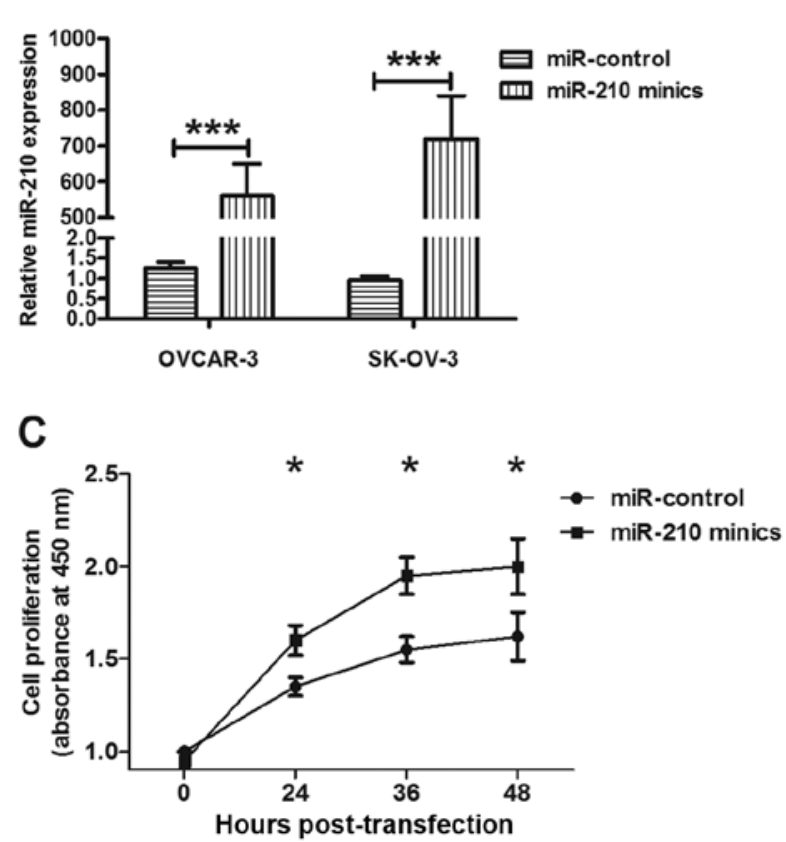

B
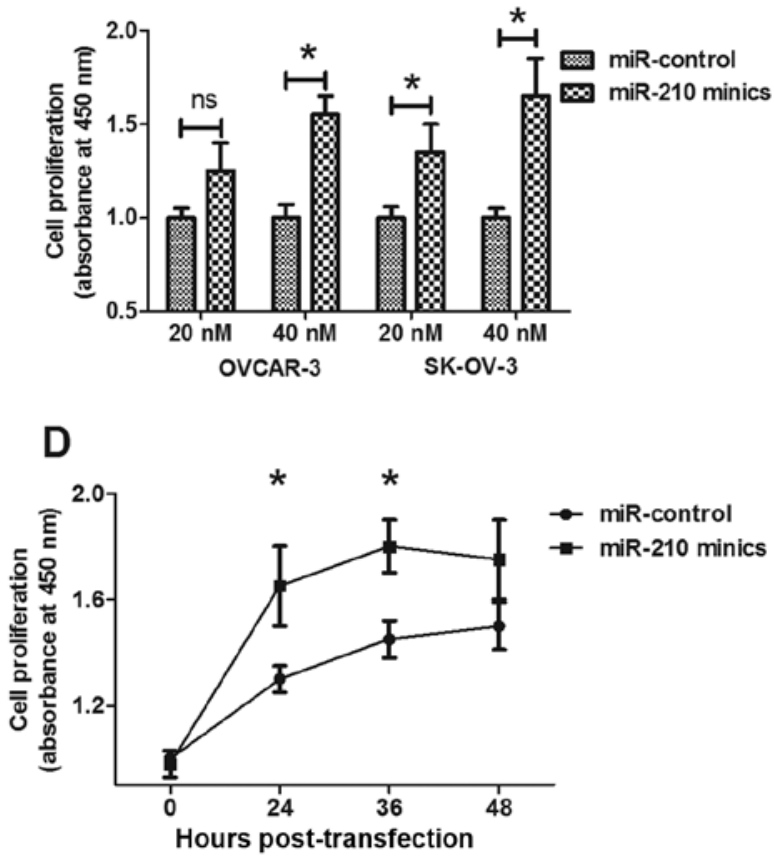

Figure 3. Overexpression of miR-210 promotes the cellular proliferation of EOC cells in vitro. (A) The manipulation of miR-210 expression in OVCAR-3 and SK-OV-3 cells. miR-210 was examined by RT-qPCR, $24 \mathrm{~h}$ post-transfection with $20 \mathrm{nM}$ miR-control or miR-210 mimics. (B) The relative cellular proliferation of OVCAR-3 or SK-OV-3 cells 24 h post miR-210 mimics or miR-control transfection at 20 or 50 nM, revealed by CCK-8 assay. (C and D) Growth curve of cell proliferation was made after transfection with miR-210 mimics or miR-control in (C) OVCAR-3 or (D) SK-OV-3 cells, examined by CCK-8 assay. The experiments were performed separately in triplicate. Statistical significance, ${ }^{*} \mathrm{p}<0.05,{ }^{* *} \mathrm{p}<0.01$ and ${ }^{* * * *} \mathrm{p}<0.001$.

miR-210 upregulates the viability and growth of ovarian cancer cells in vitro. To determine the possible contribution of miR-210 to EOC cell proliferation, we manipulated the miR-210 expression level in OVCAR-3 and SK-OV-3 cell lines by transfecting with miR-210 mimics or miRNA control. The significant increase of miR-210 in OVCAR-3 and SK-OV-3 cells post transfection with miR-210 mimics is shown in Fig. 3A (both $\mathrm{p}<0.01$ ). Then, the proliferation of OVCAR-3 and SK-OV-3 cells post-miR-210 mimics or miRNA control was tested by CCK-8 assay. Both in OVCAR-3 and in SK-OV-3 cells, the miR-210 mimics promoted cell proliferation rather than miRNA control time-dependently (Fig. 3B and $\mathrm{C}$ ). We also detected the differences in colony formation of OVCAR-3 and SK-OV-3 cells transfected with miR-210 mimics or miRNA control. Fig. 4 shows the higher capability of colony formation for both cell lines post-transfection with miR-210 mimics than post-transfection with miRNA control. The above findings demonstrated that upregulated miR-210 enhanced the proliferative capability and colony formation of EOC cells in vitro.

miR-210 ameliorates the hypoxia-induced apoptosis in ovarian cancer cells in vitro. Hypoxia induces apoptosis via HIF-1 $\alpha$ (45-47), in various tumor cells, including ovarian cancer (48). The most direct induction of hypoxia-induced apoptosis is the inhibition of the electron transport chain at the inner membrane of the mitochondria. We tested the sensitivity of OVCAR-3 or in SK-OV-3 ovarian cancer cells to 5-FU. At normoxia culture conditions, the 5-FU induced low level of apoptosis with a slight time-dependent increase, while hypoxia costimulates higher level of apoptosis with 5-FU in both cell types (Fig. 5A and B). We also tested in OVCAR-3 cells, the expression of caspase 3 (CASP3) and caspase 9 (CASP9), both of which are executional molecules in apoptosis. The western blot analysis results demonstrated that significantly high levels of CASP3 and CASP9 were induced by a low dose of 5-FU under hypoxic culture condition rather than in normoxia (Fig. 5C and D). However, the hypoxia-induced apoptosis could be reversed by miR-210 inhibitor, the increase in apoptotic rate and the expression level of CASP3 or CASP9 were blocked by the miR-210 inhibitor transfecion (Fig. 5E-H).

PTPN1 is downregulated during the miR-210-mediated antiapoptosis. To unveil the anti-apoptosis effect of miR-210, we predicted the possible targets of miR-210 by miRanda. PTPN1 is one of the screened targets, and has not been determined to play roles in ovarian cancer, though it is well known to induce apoptosis (49-52). To evaluate the possible targeting of PTPN1 by miR-210 in ovarian cancer cells, the PTPN1 expression in mRNA and protein levels was determined with the miR-210 mimics or miRNA control transfection in OVCAR-3 or SK-OV-3 cells. It was shown that the pro-apoptotic protein was downregulated after transfection with miR-210 mimics while there was no effect for the control transfection (Fig. 6A and B). Fig. 6C shows that PTPN1 had a consequential pairing with the miR-210. To reconfirm the PTPN1 downregulation by miR-210, we construct a luciferase reporter constructs containing the miR-210 recognition sequence of PTPN1 mRNA (Fig. 6C). As shown in Fig. 6D, transfection with the miR-210 mimics suppressed, while the miRNA control did 
A

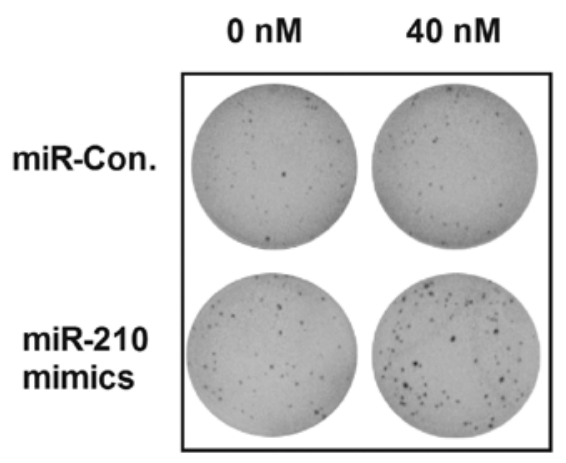

C

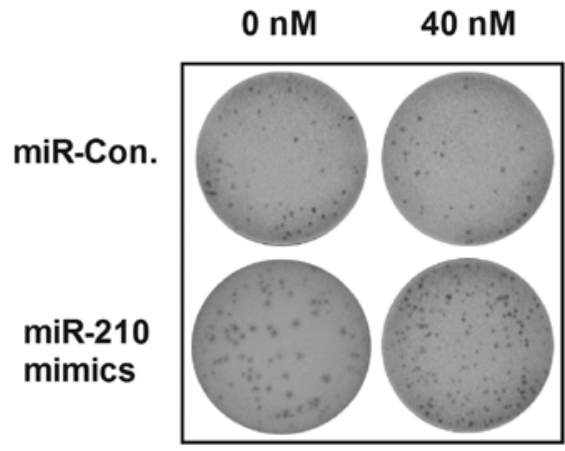

B

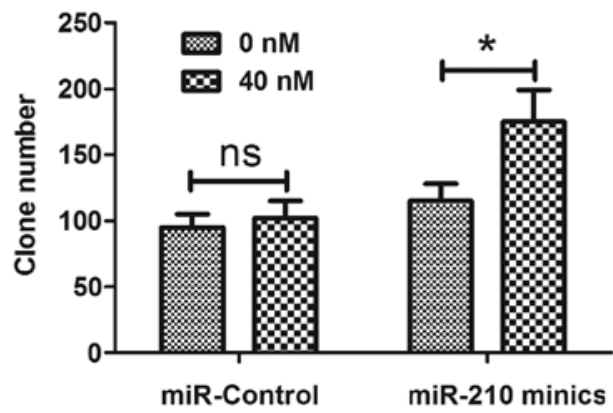

D

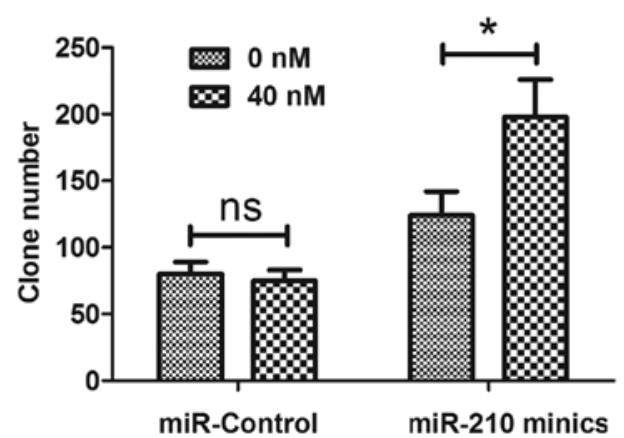

Figure 4. miR-210 upregulation stimulates the colony formation of EOC cells in vitro. Colony formation by OVCAR-3 or SK-OV-3 cells was determined post-transfection with 0 or $40 \mathrm{nM}$ of miR-210 mimics or miR-control. The morphologic characteristics are shown of clones (A) in OVCAR-3 cells or (C) SK-OV-3 cells. The number of colones formed in (B) OVCAR-3 cells or (D) SK-OV-3 cells was calculated as comparison. The experiments were performed separately in triplicate. Statistical significance: $n s$, no significance; ${ }^{*} \mathrm{p}<0.05$.

not regulate the activity of pGL3-PTPN1 reporter in OVCAR-3 cells; and the miR-210 mimics had no suppression effect on the luciferase activity of pGL3-PTPN $1_{\text {mut }}$ reporter. These results agree with the fact that miR-210 regulates PTPN1 by targeting the 3'-UTR and inducing translation repression of the gene. Therefore, suppression of the particular gene contributes to the improvement of ovarian cancer by inhibiting apoptosis of ovarian cancer cells under hypoxia.

\section{Discussion}

In the present study, we showed that expression of miR-210 is upregulated with an association to HIF-1 $\alpha$ overexpression in clinical EOC specimens as well as EOC cell lines. The upregulated miR-210 in EOC specimens correlated with tumor stage and the post-operative residual tumor size. Results also demonstrated that the upregulated miR-210 promoted tumor cell proliferation and clone generation in vitro via targeting PTPN1 and inhibiting apoptosis. Therefore, our results indicate that the level of miR-210 expression may serve as a clinical maker for the degree of tumor growth in vivo. The deregulated solid tumor growth brings a hypoxic microenvironment, which drives tumor cells to undergo genetic and adaptive changes that allow them to adapt to the hypoxia in their milieu. The present study provides evidence that miR-210 is involved in a key hypoxia responsive network in ovarian cancer. In order to expand our understanding of the regula- tory networks involved in hypoxia response, we determined the possible miR-210 target PTPN1 effect of the blockage. The in vitro results in EOC cell lines showed manipulated overexpression of miR-210 significantly silenced the PTPN1, and blocked its proapoptotic effect. Therefore, our finding add to the knowledge on the mechanism of ovarian cancer adaptation to hypoxia.

Considering the slight response to chemotherapy of EOC, we have attempted to identify novel biomarkers for therapeutic response and molecular targets to increase sensitivity to treatment. miRs, a class of gene regulators, have been proven by accumulated evidence to be effective in regulating tumorigenesis, tumor growth, migration and even metastasis (53). Data on ovarian cancer thus far indicate that the miR network is very important to the understanding of ovarian cancer biology and resistance to therapy $(54,55)$. The hypoxia microenvironment posing for almost all tumors has become one of the key issues in the study of tumor physiology, and focused our attention on miR-210, which has been proved upregulated in various cancers (38-40). Giannakakis et al confirmed the miR-210 upregulation in ovarian cancer lines under hypoxia condition in vitro but surprisingly not in clinical ovarian cancer specimens (56). Further determination by them showed that there was a remarkably high frequency of miR-210 gene copy deletions in ovarian cancer patients. However, in the present study, we found there was a miR-210 upregulation in Chinese EOC specimens by both test methods. 
A

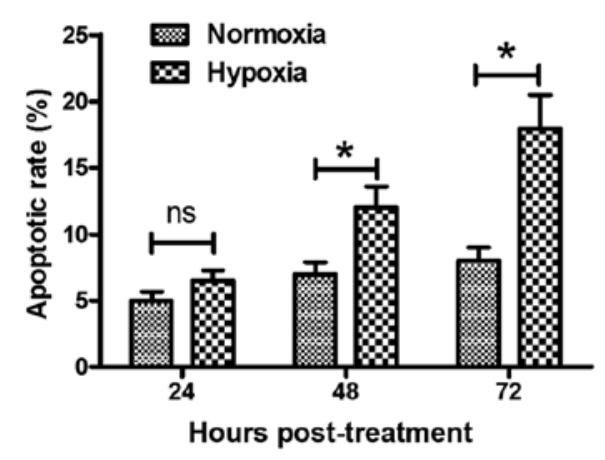

C

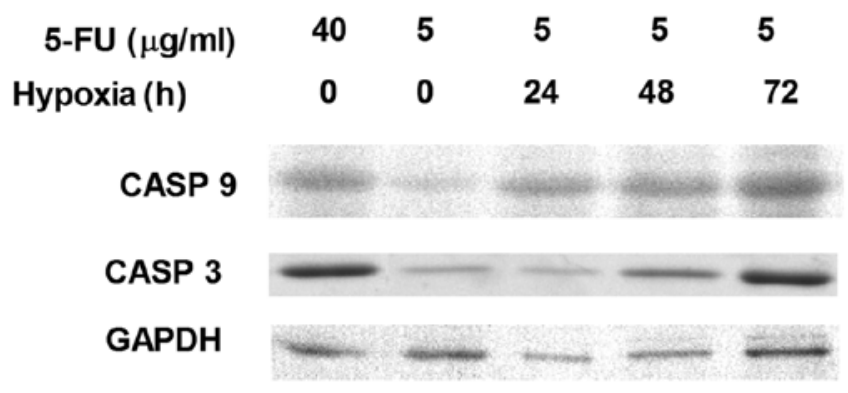

E

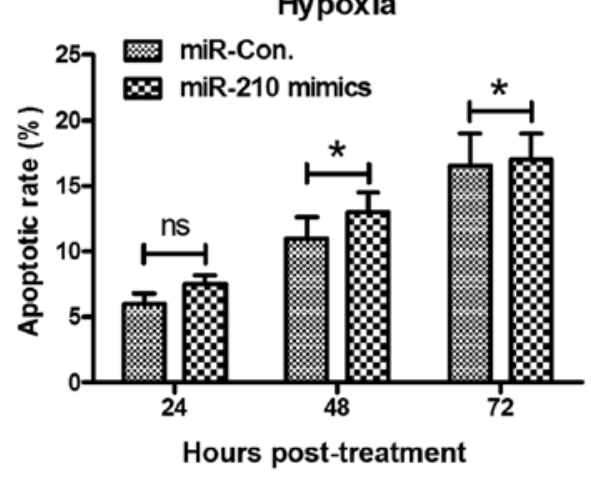

G

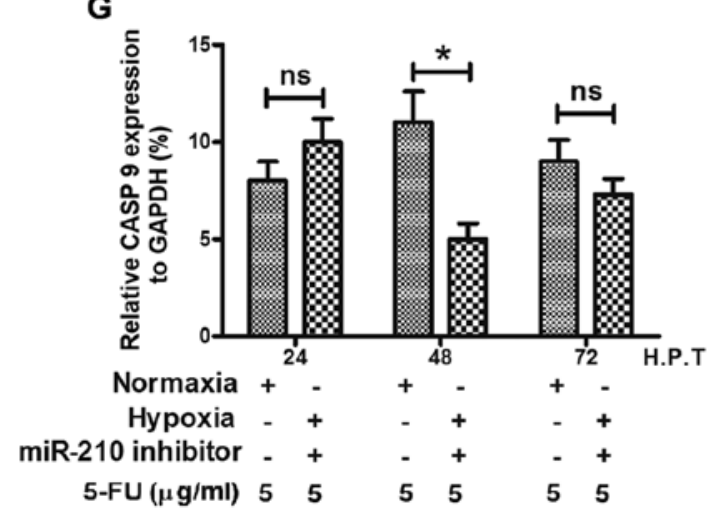

B

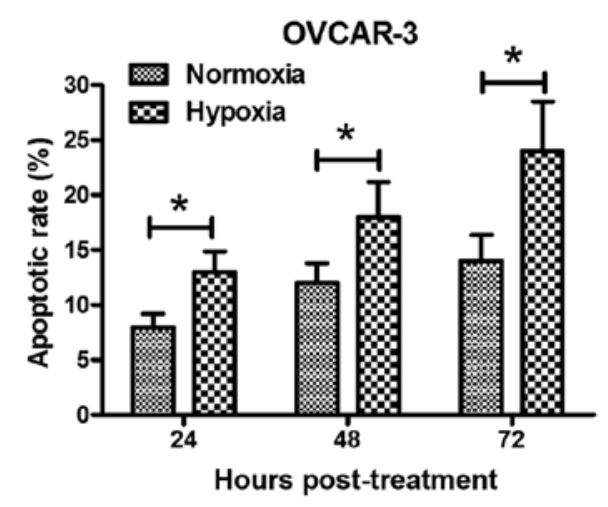

D

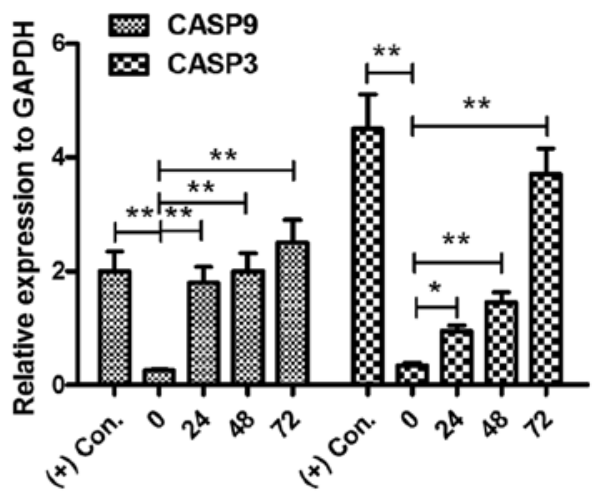

F

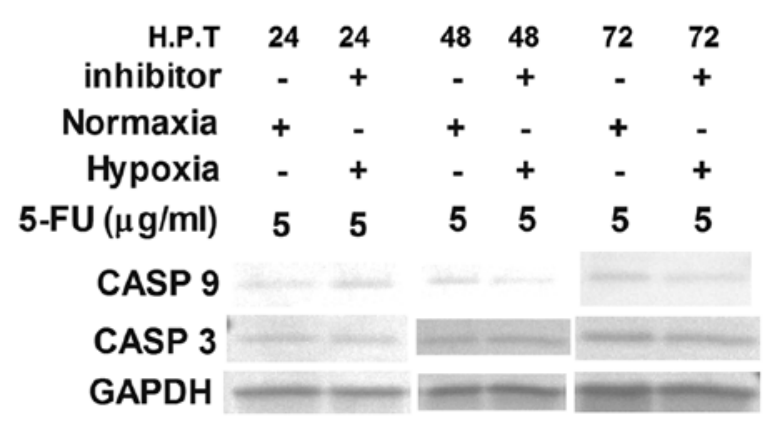

H

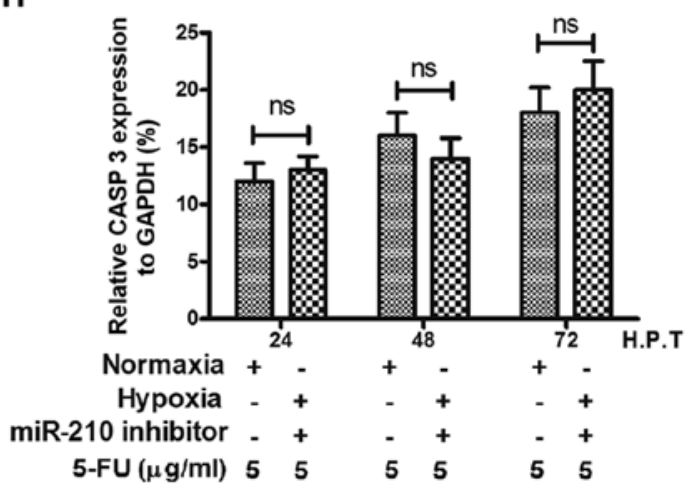

Figure 5. miR-210 knockdown ameliorates hypoxia-induced apoptosis in EOC cells in vitro. (A and B) Hypoxia-induced apoptosis in (A) SK-OV-3 or (B) OVCAR-3 cells. Cells were treated with $5 \mu \mathrm{g} / \mathrm{ml} 5$-FU under normoxia or hypoxia condition for 24,48 or $72 \mathrm{~h}$, then the apoptotic cells were counted by a FACScan flow cytometer. (C) Western blot determination of CASP3 and CASP9 expression induced by hypoxia. (D) Relative CASP9 or CASP3 expression was calculated and expressed as percentage to GAPDH. (E and F) miR-210 knockdown ameliorates the hypoxia-induced apoptosis (E) or inhibits apoptotic marker expression (F) in OVCAR-3 cells. Cells were transfected with $20 \mathrm{nM}$ of miR-210 inhibitor, and were treated with $5 \mu \mathrm{g} / \mathrm{ml} 5$-FU, under normoxia or hypoxia condition for 24,48 or $72 \mathrm{~h}$, then the apoptotic cells were counted by a FACScan flow cytometer; CASP 3 and CASP9 expression were determined by western blot analysis. (G and H) Relative $(\mathrm{G})$ CASP9 or (H) CASP3 expression to GAPDH was calculated. The results are the average of three experiments. Statistical significance: as: ns, no significance; ${ }^{*} \mathrm{p}<0.05$. 
A

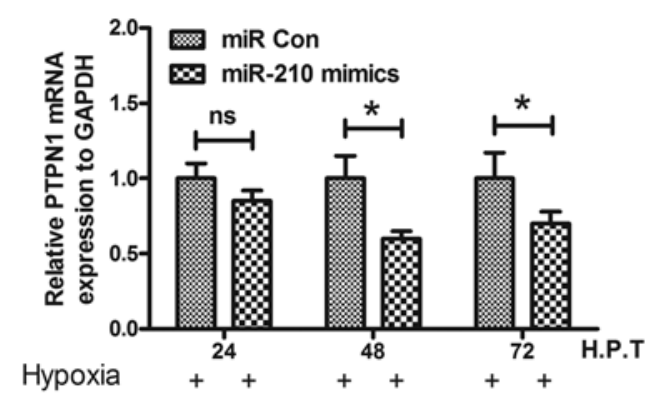

B

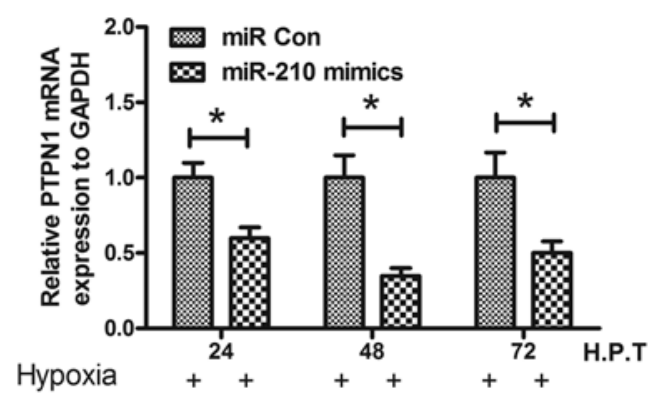

\section{C}

\begin{tabular}{|c|c|c|c|c|c|}
\hline $\begin{array}{l}\text { Duplex } \\
\text { structure }\end{array}$ & Predicted consequential pairing of miRNA and target regions & Sites & Score & MFE & \\
\hline $\begin{array}{l}\text { miRNA } \\
\text { Target }\end{array}$ & 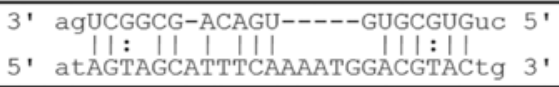 & $1655-1682$ & 112.00 & -10.10 & pGL3-PTPN1-UTR \\
\hline $\begin{array}{l}\text { miRNA } \\
\text { Target }\end{array}$ & 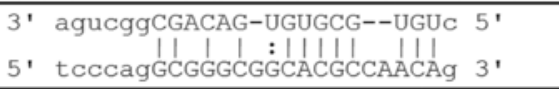 & $334-358$ & 112.00 & -18.50 & $\begin{array}{l}\text { gcgggcggcacgccaaca+ } \\
\text { ccgcagagcccacgccc }\end{array}$ \\
\hline $\begin{array}{l}\text { miRNA } \\
\text { Target }\end{array}$ & $\begin{array}{l}3^{\prime} \text { agucGGCGAC-AGUGUGCGUGUC } 5^{\prime} \\
5^{\prime} \text { ctgCCCGCAGAGCCCACGCCCǴa } 3{ }^{\prime} \\
\end{array}$ & $44-66$ & 110.00 & -14.00 & $\begin{array}{l}\text { | pGL3-PTPN1 } \text { mut }^{\text {-UTR }} \\
\text { gcgggcgg }^{\text {tgtat }} \text { caaca+ccgcagagcc } \\
\text { tgtat } \\
\text { gc }\end{array}$ \\
\hline
\end{tabular}

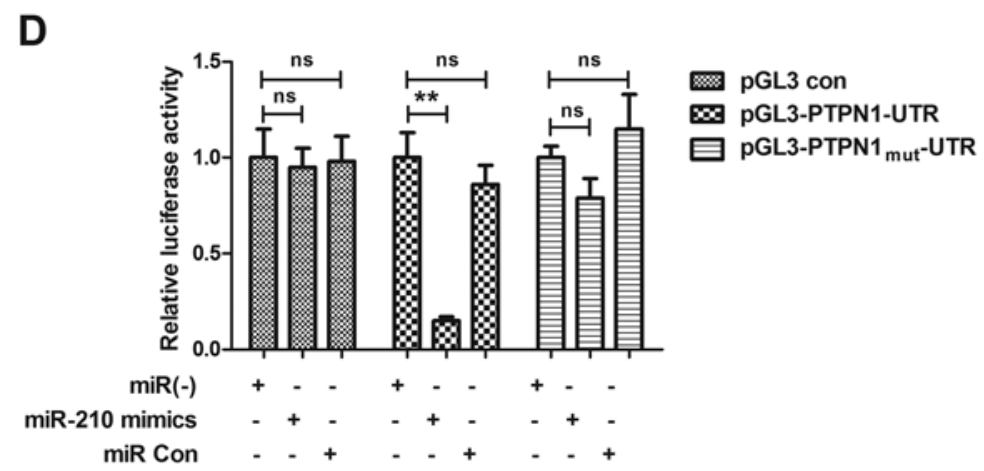

Figure 6. miR-210 targets 3'-UTR of PTPN1 and reduces PTPN1 mRNA. PTPN1 mRNA was reduced in (A) SK-OV-3 and (B) OVCAR-3 cells post-transfection with miR-210 mimics. (C) miR-210 /PTPN1 alignment by miRanda analysis and the schematic diagram of the PTPN1/pGL3-PTPN1 ${ }_{\text {mut }}$ paired sequences for miR-210. (D) Relative luciferase activity of pGL-PTPN1/pGL3-PTPN1 ${ }_{\text {mut }}$ reporter or pGL-con vector in OVCAR-3 cells tranfected with miR-21 mimics. The experiments were performed in triplicate. Statistical significance: ${ }^{*} \mathrm{p}<0.05$ and ${ }^{* *} \mathrm{p}<0.01$; ns, no significance.

Interestingly, the miR-210 upregulation correlated with a higher tumor stage or larger post-operative residual tumor size, the miR-210 expression was not significantly upregulated in the specimens of cancer with lower stage or postoperative residual tumor size. Therefore, the hypoxia-induced miR-210 upregulation might correlate with other parameters and needs to be further determined.

miR-210 has been strongly linked with the hypoxia condition and is upregulated by hypoxia-inducible factors (57). It is also overexpressed in cells affected by cardiac disease and tumors (58). miR-210 in particular, has been well studied for its effects in rescuing cardiac function after myocardial infarcts via the upregulation of angiogenesis and inhibition of cardiomyocyte apoptosis (59). Accumulated data show that it is significantly upregulated in various kinds of tumors, such as head and neck paragangliomas (38), lung cancer cells (39) and breast cancer cells (40). The upregulated miR-210 regulates cancer proliferation, via its anti-apoptotic effect
(41), modulating angiogenesis (60). The anti-apoptotic effect of miR-210 was achieved by inhibiting the target genes, such as EFNA3 (61), ISCU (62), E2F3 (63) and FGFRL1 (57). More recently, it was shown that miR-210 could target the tyrosineprotein phosphatase non-receptor type 1 (PTPN1), also known as protein tyrosine phosphatase-1B (PTP1B) protein and regulates the susceptibility of tumor cells to lysis by cytotoxic T cells (64). The PTPN1 is known to induce apoptosis through the downregulation of pro-survival RTK signaling $(49,50)$, the enhancement of ER stress signaling (51), or the facilitation of caspase 8/9 activities (52). However, up to now, little was known of the regulation of miR-210 under hypoxia situation in ovarian cancer cells and about actions of miR-210 on ovarian cancer modulating. It is not clear whether miR-210 targets PTPN1 and inhibits apoptosis in ovarian cancer or other tumor cells. The present study firstly demonstrated that the upregulated miR-210 in EOCs promoted tumor cell proliferation and clone generation in vitro via targeting PTPN1 and 
inhibiting apoptosis. It implied that the EOCs with a higher level of miR-210 may be more aggresive in vivo.

In summary, miR-210 expression is upregulated, in response to a hypoxia condition, and with an association to HIF-1 $\alpha$ overexpression in clinical EOC specimens as well as EOC cell lines. The upregulated miR-210 promoted the tumor growth in vitro via targeting PTPN1 and inhibiting apoptosis. Therefore, our finding provide new information on the mechanism of ovarian cancer adaptation to hypoxia.

\section{Acknowledgements}

This study was supported by a grant from Chinese PLA General Hospital.

\section{References}

1. Jemal A, Bray F, Center MM, Ferlay J, Ward E and Forman D Global cancer statistics. CA Cancer J Clin 61: 69-90, 2011.

2. Colombo N, Van Gorp T, Parma G, et al: Ovarian cancer. Crit Rev Oncol Hematol 60: 159-179, 2006.

3. Moss C and Kaye SB: Ovarian cancer: progress and continuing controversies in management. Eur J Cancer 38: 1701-1707, 2002.

4. Hockel $\mathrm{M}$ and Vaupel P: Tumor hypoxia: definitions and current clinical, biologic, and molecular aspects. J Natl Cancer Inst 93 266-276, 2001.

5. Dang CV and Semenza GL: Oncogenic alterations of metabolism. Trends Biochem Sci 24: 68-72, 1999.

6. Harris AL: Hypoxia - a key regulatory factor in tumour growth. Nat Rev Cancer 2: 38-47, 2002.

7. Cummins EP and Taylor CT: Hypoxia-responsive transcription factors. Pflugers Arch 450: 363-371, 2005.

8. Licausi F, Weits DA, Pant BD, Scheible WR, Geigenberger P and van Dongen JT: Hypoxia responsive gene expression is mediated by various subsets of transcription factors and miRNAs that are determined by the actual oxygen availability. New Phytol 190: 442-456, 2011.

9. Semenza GL: Targeting HIF-1 for cancer therapy. Nat Rev Cancer 3: 721-732, 2003.

10. Christofk HR, Vander Heiden MG, Harris MH, et al: The M2 splice isoform of pyruvate kinase is important for cancer metabolism and tumour growth. Nature 452: 230-233, 2008.

11. Wang GL, Jiang $B H$, Rue EA and Semenza GL: Hypoxia-inducible factor 1 is a basic-helix-loop-helix-PAS heterodimer regulated by cellular $\mathrm{O}_{2}$ tension. Proc Natl Acad Sci USA 92: 5510-5514, 1995.

12. Pouyssegur J, Dayan F and Mazure NM: Hypoxia signalling in cancer and approaches to enforce tumour regression. Nature 441: 437-443, 2006

13. Kaelin WG Jr and Ratcliffe PJ: Oxygen sensing by metazoans: the central role of the HIF hydroxylase pathway. Mol Cell 30 : 393-402, 2008.

14. Blancher C, Moore JW, Talks KL, Houlbrook S and Harris AL: Relationship of hypoxia-inducible factor (HIF)-1alpha and HIF-2alpha expression to vascular endothelial growth factor induction and hypoxia survival in human breast cancer cell lines. Cancer Res 60: 7106-7113, 2000.

15. Zhong H, De Marzo AM, Laughner E, et al: Overexpression of hypoxia-inducible factor lalpha in common human cancers and their metastases. Cancer Res 59: 5830-5835, 1999.

16. Hanahan D and Folkman J: Patterns and emerging mechanisms of the angiogenic switch during tumorigenesis. Cell 86 353-364, 1996.

17. Pralhad T, Madhusudan S and Rajendrakumar K: Concept, mechanisms and therapeutics of angiogenesis in cancer and other diseases. J Pharm Pharmacol 55: 1045-1053, 2003.

18. Carmeliet P and Jain RK: Angiogenesis in cancer and other diseases. Nature 407: 249-257, 2000.

19. Semenza GL: HIF-1 and tumor progression: pathophysiology and therapeutics. Trends Mol Med 8: S62-S67, 2002.

20. Chi JT, Wang Z, Nuyten DS, et al: Gene expression programs in response to hypoxia: cell type specificity and prognostic significance in human cancers. PLoS Med 3: e47, 2006.
21. Imai $\mathrm{T}$, Horiuchi $\mathrm{A}$, Wang $\mathrm{C}$, et al: Hypoxia attenuates the expression of E-cadherin via up-regulation of SNAIL in ovarian carcinoma cells. Am J Pathol 163: 1437-1447, 2003.

22. Horiuchi A, Imai T, Shimizu M, et al: Hypoxia-induced changes in the expression of VEGF, HIF-1 alpha and cell cyclerelated molecules in ovarian cancer cells. Anticancer Res 22: 2697-2702, 2002.

23. Horiuchi A, Hayashi T, Kikuchi N, et al: Hypoxia upregulates ovarian cancer invasiveness via the binding of HIF-1alpha to a hypoxia-induced, methylation-free hypoxia response element of S100A4 gene. Int J Cancer 131: 1755-1767, 2012.

24. Osada R, Horiuchi A, Kikuchi N, et al: Expression of hypoxia-inducible factor 1alpha, hypoxia-inducible factor 2alpha, and von Hippel-Lindau protein in epithelial ovarian neoplasms and allelic loss of von Hippel-Lindau gene: nuclear expression of hypoxia-inducible factor lalpha is an independent prognostic factor in ovarian carcinoma. Hum Pathol 38: 1310-1320, 2007.

25. Ambros V: MicroRNA pathways in flies and worms: growth, death, fat, stress, and timing. Cell 113: 673-676, 2003.

26. Bartel DP: MicroRNAs: target recognition and regulatory functions. Cell 136: 215-233, 2009.

27. Brennecke J, Hipfner DR, Stark A, Russell RB and Cohen SM: Bantam encodes a developmentally regulated microRNA that controls cell proliferation and regulates the proapoptotic gene hid in Drosophila. Cell 113: 25-36, 2003.

28. Reinhart BJ, Slack FJ, Basson M, et al: The 21-nucleotide let-7 RNA regulates developmental timing in Caenorhabditis elegans. Nature 403: 901-906, 2000

29. Jay C, Nemunaitis J, Chen P, Fulgham P and Tong AW: miRNA profiling for diagnosis and prognosis of human cancer. DNA Cell Biol 26: 293-300, 2007.

30. Yu SL, Chen HY, Yang PC and Chen JJ: Unique microRNA signature and clinical outcome of cancers. DNA Cell Biology 26: 283-292, 2007.

31. Qiang R, Wang F, Shi LY, et al: Plexin-B1 is a target of miR-214 in cervical cancer and promotes the growth and invasion of HeLa cells. Int J Biochem Cell Biol 43: 632-641, 2011.

32. Au Yeung CL, Tsang TY, Yau PL and Kwok TT: Human papillomavirus type 16 E6 induces cervical cancer cell migration through the p53/microRNA-23b/urokinase-type plasminogen activator pathway. Oncogene 30: 2401-2410, 2011.

33. Xu CX, Xu M, Tan L, et al: MicroRNA miR-214 regulates ovarian cancer cell stemness by targeting p53/Nanog. J Biol Chem 287: 34970-34978, 2012.

34. Ye G, Fu G, Cui S, et al: MicroRNA 376c enhances ovarian cancer cell survival by targeting activin receptor-like kinase 7 : implications for chemoresistance. J Cell Sci 124: 359-368, 2011.

35. Vecchione A, Belletti B, Lovat F, et al: A microRNA signature defines chemoresistance in ovarian cancer through modulation of angiogenesis. Proc Natl Acad Sci USA 110: 9845-9850, 2013.

36. Mutharasan RK, Nagpal V, Ichikawa Y and Ardehali H: microRNA-210 is upregulated in hypoxic cardiomyocytes through Akt- and p53-dependent pathways and exerts cytoprotective effects. Am J Physiol Heart Circ Physiol 301: H1519-H1530, 2011.

37. Biswas S, Roy S, Banerjee J, et al: Hypoxia inducible microRNA 210 attenuates keratinocyte proliferation and impairs closure in a murine model of ischemic wounds. Proc Natl Acad Sci USA 107: 6976-6981, 2010.

38. Merlo A, de Quiros SB, Secades P, et al: Identification of a signaling axis HIF-1alpha/microRNA-210/ISCU independent of SDH mutation that defines a subgroup of head and neck paragangliomas. J Clin Endocrinol Metab 97: E2194-E2200, 2012 .

39. Wang H, Bian S and Yang CS: Green tea polyphenol EGCG suppresses lung cancer cell growth through upregulating miR-210 expression caused by stabilizing HIF-1alpha. Carcinogenesis 32: 1881-1889, 2011.

40. Camps C, Buffa FM, Colella S, et al: hsa-miR-210 is induced by hypoxia and is an independent prognostic factor in breast cancer. Clin Cancer Res 14: 1340-1348, 2008

41. Gou D, Ramchandran R, Peng X, et al: $\mathrm{miR}-210$ has an antiapoptotic effect in pulmonary artery smooth muscle cells during hypoxia. Am J Physiol Lung Cell Mol Physiol 303: L682-L691, 2012.

42. Fasanaro P, D'Alessandra Y, Di Stefano V, et al: MicroRNA-210 modulates endothelial cell response to hypoxia and inhibits the receptor tyrosine kinase ligand Ephrin-A3. J Biol Chem 283: 15878-15883, 2008. 
43. Livak KJ and Schmittgen TD: Analysis of relative gene expression data using real-time quantitative PCR and the 2(-Delta Delta C(T)) method. Methods 25: 402-408, 2001.

44. Kim SW, Li Z, Moore PS, et al: A sensitive non-radioactive northern blot method to detect small RNAs. Nucleic Acids Res 38: e98, 2010.

45. Greijer AE and van der Wall E: The role of hypoxia inducible factor 1 (HIF-1) in hypoxia induced apoptosis. J Clin Pathol 57: 1009-1014, 2004.

46. Carmeliet P, Dor Y, Herbert JM, et al: Role of HIF-1alpha in hypoxia-mediated apoptosis, cell proliferation and tumour angiogenesis. Nature 394: 485-490, 1998.

47. Moritz W, Meier F, Stroka DM, et al: Apoptosis in hypoxic human pancreatic islets correlates with HIF-lalpha expression. FASEB J 16: 745-747, 2002.

48. Zhu P, Ning Y, Yao L, Chen $\mathrm{M}$ and $\mathrm{Xu} \mathrm{C}$ : The proliferation, apoptosis, invasion of endothelial-like epithelial ovarian cancer cells induced by hypoxia. J Exp Clin Cancer Res 29: 124, 2010.

49. Sangwan V, Paliouras GN, Cheng A, Dube N, Tremblay ML and Park M: Protein-tyrosine phosphatase 1B deficiency protects against Fas-induced hepatic failure. J Biol Chem 281: 221-228, 2006.

50. Gonzalez-Rodriguez A, Escribano O, Alba J, Rondinone CM, Benito $M$ and Valverde AM: Levels of protein tyrosine phosphatase 1B determine susceptibility to apoptosis in serumdeprived hepatocytes. J Cell Physiol 212: 76-88, 2007.

51. Gu F, Nguyen DT, Stuible M, Dube N, Tremblay ML and Chevet E: Protein-tyrosine phosphatase 1B potentiates IRE1 signaling during endoplasmic reticulum stress. J Biol Chem 279: 49689-49693, 2004.

52. Akasaki Y, Liu G, Matundan HH, et al: A peroxisome proliferator-activated receptor-gamma agonist, troglitazone, facilitates caspase -8 and -9 activities by increasing the enzymatic activity of protein-tyrosine phosphatase-1B on human glioma cells. J Biol Chem 281: 6165-6174, 2006.

53. Iorio $\mathrm{MV}$ and Croce CM: microRNA involvement in human cancer. Carcinogenesis 33: 1126-1133, 2012.
54. Dahiya N and Morin PJ: MicroRNAs in ovarian carcinomas. Endocr Relat Cancer 17: F77-F89, 2010

55. Shih KK, Qin LX, Tanner EJ, et al: A microRNA survival signature (MiSS) for advanced ovarian cancer. Gynecol Oncol 121: 444-450, 2011.

56. Giannakakis A, Sandaltzopoulos R, Greshock J, et al: miR-210 links hypoxia with cell cycle regulation and is deleted in human epithelial ovarian cancer. Cancer Biol Ther 7: 255-264, 2008.

57. Tsuchiya S, Fujiwara T, Sato F, et al: MicroRNA-210 regulates cancer cell proliferation through targeting fibroblast growth factor receptor-like 1 (FGFRL1). J Biol Chem 286: 420-428, 2011.

58. Li T, Cao H, Zhuang J, et al: Identification of miR-130a, miR-27b and miR-210 as serum biomarkers for atherosclerosis obliterans. Clin Chim Acta 412: 66-70, 2011.

59. Puissegur MP, Mazure NM, Bertero T, et al: miR-210 is overexpressed in late stages of lung cancer and mediates mitochondrial alterations associated with modulation of HIF-1 activity. Cell Death Differ 18: 465-478, 2011.

60. Ramon LA, Braza-Boils A, Gilabert J, et al: microRNAs related to angiogenesis are dysregulated in endometrioid endometrial cancer. Hum Reprod 27: 3036-3045, 2012.

61. Chen WY, Liu WJ, Zhao YP, et al: Induction, modulation and potential targets of miR-210 in pancreatic cancer cells. Hepatobiliary Pancreat Dis Int 11: 319-324, 2012.

62. Favaro E, Ramachandran A, McCormick R, et al: MicroRNA-210 regulates mitochondrial free radical response to hypoxia and krebs cycle in cancer cells by targeting iron sulfur cluster protein ISCU. PLoS One 5: e10345, 2010.

63. Nakada C, Tsukamoto Y, Matsuura K, et al: Overexpression of miR-210, a downstream target of HIFlalpha, causes centrosome amplification in renal carcinoma cells. J Pathol 224: 280-288, 2011.

64. Noman MZ, Buart S, Romero P, et al: Hypoxia-inducible miR-210 regulates the susceptibility of tumor cells to lysis by cytotoxic T cells. Cancer Res 72: 4629-4641, 2012. 